\title{
Redução da Contaminação Microbiana de Carne Moída Resfriada "In Natura" Utilizando A Radiação por Micro-Ondas
}

Gabriela Poletto (I), Maria Fernanda da Silveira Cáceres de Menezes (I), Greice Carine Raddatz (I), Thaiane Marques da Silva (I), Mariana de Araújo Etchepare (I), Carlos Pasqualin Cavalheiro (I), Caroline Posser Simeoni (I), Juliano Smanioto Barin (I), Alexandre José Cichoski (I), Cristiano Ragagnin de Menezes (I)

(I) UFSM - Universidade Federal de Santa Maria (Avenida Roraima)

\section{Resumo}

Os produtos alimentícios de origem animal, em especial a carne bovina, são facilmente contaminados antes, durante e após o processamento. As contaminações provocadas durante o processamento promovem alterações no valor nutricional e nas características sensoriais. A excessiva manipulação e o abuso de temperatura durante o processamento da carne moída a tornam um alimento propício a alterações microbianas, neste intuito, a utilização de novas tecnologias, como a radiação de micro-ondas merece uma considerável atenção, pois está sendo utilizada como método alternativo aos processos convencionais de conservação.Nesse contexto, o objetivo desse trabalho foi analisar o efeito da radiação de micro-ondas na redução da microbiota de carne moída resfriada "in natura" bovina e aumento da sua vida de prateleira. As amostras de carne moída foram submetidas a diferentes tratamentos: um controle (sem radiação) e três tratamentos com o uso de radiação de micro-ondas, por 10 e 20 segundos nas potências 10\%, 20\% 100\% da sua capacidade de emissão de energia eletromagnética. Utilizou-se um equipamento de micro-ondas convencional doméstico, modelo MS3042RA, 38L, $2450 \mathrm{MHz}$, potência de saída 800W, marca LG. Neste trabalho foram realizadas avaliações microbiológicas de

\footnotetext{
Referência:

Gabriela Poletto, Maria Fernanda da Silveira Cáceres de Menezes, Greice Carine Raddatz, Thaiane Marques da Silva, Mariana de Araújo Etchepare, Carlos Pasqualin Cavalheiro, Caroline Posser Simeoni, Juliano Smanioto Barin, Alexandre José Cichoski, Cristiano Ragagnin de Menezes. Redução da Contaminação Microbiana de Carne Moída Resfriada "In Natura" Utilizando A Radiação por Micro-Ondas. In: Anais do 12ㅇ Congresso Latinoamericano de Microbiologia e Higiene de Alimentos - MICROAL 2014 [= Blucher Food Science Proceedings, num.1, vol.1]. São Paulo: Editora Blucher, 2014. 
micro-organismos mesófilos aeróbios totais em carne moída resfriada "in natura" bovina, proveniente de estabelecimentos comerciais do município de Santa Maria (RS). A contagem microbiológica da amostra controle foi de 8,82 log/UFC demostrando um índice elevado, visto que o resultado desta avaliação demonstra a qualidade higiênico-sanitária do produto. Os resultados das contagens microbiológicas das amostras tratadas nas diferentes potências, $10 \%, 20 \%$ e 100\%, foram submetidos à análise de variância e as comparações entre os tratamentos foram realizadas utilizando o teste de Tukey $(\mathrm{p}<0,05)$. Os três tratamentos demonstraram uma redução de $2 \log$ /UFC de micro-organismos mesófilos aeróbios totais quando comparados com o grupo controle, no entanto, o tratamento que utilizou o micro-ondas com $20 \%$ da potência pelo tempo de 10 segundos foi o mais significativo para a redução microbiana 6,14 log/UFC. Apesar de não haver exigência pela legislação vigente de análises de microorganismos mesófilos aeróbios totais para carne resfriada "in natura", a literatura sugere $6 \log /$ UFC como limite máximo destas contagens no produto.

Palavras-Chave: carne moída, micro-ondas, radiação, redução microbiana Agência de Fomento: 